\title{
Research on Effectiveness of the Government R\&D Subsidies: Evidence from Large and Medium Enterprises in China
}

\author{
Xindong Zhang, Junjun Wu \\ School of Economics and Management, Shanxi University, Taiyuan, China \\ Email: zhangxd@sxu.edu.cn, 634857298@qq.com
}

Received 22 June 2014; revised 28 July 2014; accepted 30 August 2014

Copyright $@ 2014$ by authors and Scientific Research Publishing Inc.

This work is licensed under the Creative Commons Attribution International License (CC BY). http://creativecommons.org/licenses/by/4.0/

(c) (i) Open Access

\begin{abstract}
To cope with the fast-changing business environment, Chinese government makes every effort to increase business R\&D subsidies. The aim of this paper is to examine the efficiency of Chinese government $R \& D$ subsidies on innovative performance and the moderating role of a firm's $R \& D$ capacity. Based on the data from Chinese Large and Medium Firms during 1997-2012, we analyze whether government R\&D subsidies affect a firm's innovative performance, as well as how this effect works. The findings suggest that the firms that received increasing government R\&D subsidies will have a better innovative performance, yet up to a point. Beyond this threshold, a greater share of government R\&D subsidy will reduce a firm's innovative performance. And such substitution effect is larger for firms with greater $R \& D$ capacity. Also, the firm's own R\&D capacity, size, industry technical levels have varying degrees of impact on the efficiency of government R\&D subsidies. The findings of this paper may have practical value and help governments to develop relative regulations and policies.
\end{abstract}

\section{Keywords}

China, Government R\&D Subsidies, R\&D Capacity, Innovative Performance

\section{Introduction}

The firm becomes strong and a country will be strong. Whether we can build an upgraded version of our economic development, from "Made in China" to "Created in China", to achieve sustainable development, largely depends on the creativity of firms. As a representative country, China has begun to implement the strategy of rejuvenating a country through science and technology since mid-1990s and attached great importance to crea- 
tivity. Our governments consider financial R\&D subsidies for firms as the most significant strategy to stimulate firms' independent innovation. From Figure 1 we know, in past 20 years, Chinese government-funded science and technology for firms has increased from 1.342 billion in 1997 to 868.7 billion in 2012, an average annual growth rate of $30 \%$. The growing government subsidies have attracted much attention.

Currently, a lot of literature focused on the impact of government R\&D subsidies on private R\&D spending, incentive effect or substitution effect. But few studies concern the impact of government R\&D subsidies on innovative outputs. More rarely pay attention to the effect of government R\&D subsidies on the innovative performance and the moderating role of a firm's R\&D capacity. This paper will analyze it in two perspectives: firstly, combine with firms' R\&D capacity level to examine the influence of Chinese government R\&D subsidies on innovative performance; secondly, there has already existed literatures, making clearly that the contribution of government $R \& D$ subsidies to innovative performance will show a significant interval effect. On this basis of the research, this paper finds the optimal point through empirical analysis.

\section{Theoretical Framework}

Since the “Theory of Economic Development” by Schumpeter (1912) [1] published, innovation theory has had a profound impression on economic development. Both the Externality Theory [2] and Endogenous Growth Theory [3] hold the view that R\&D activity has the nature of public products, which makes it difficult to achieve the optimum level of social R\&D investment. So government is required to participate in R\&D activities to make up for the defect of "Market Failure". As illustrated by Romer (1990) [4] and Grossman (1991) [5], relying only on market to spur firms' innovation is difficult to achieve optimal allocation of social resources. Also R\&D activity has some basic specific features such as large investment and long payback period, which makes firms do not have enough power to engage in R\&D activities. So government funding-support system can help innovator solve the "Market Failure" problem.

Most empirical studies believe that government R\&D subsidies can promote private sector's technological innovation. For instance, Spence (1984) [6] proposed that government R\&D subsidies could reduce R\&D risk and improve a firm's R\&D motivation. Benat Bilbao-Osorio (2004) [7] discovered that R\&D activities would lead to innovation, and then innovation could promote economic growth. So in some developed countries, such as some members of OECD and America, Government R\&D subsidies were paid much attention [8]. In the mid-1990s, American government subsidies accounted for more than 50\% of firms' total R\&D investment and firms' ability to innovation significantly improved after the support of government. Recently, in USA and OECD member countries, the percentage of government-fund in firm's R\&D investment stabilized at $8 \%$ to $9 \%$ (Report of International Science and Technology Development of China, 2009) [9]. Zhu Pingfang (2003) [10] used the panel data random model to study the influence of Shanghai incentive policy to the firm's R\&D investment and patent output, the result showed that two policies, grants and tax relief had positive effect to the firms' R\&D investment. Then, with the deepening research, some scholars found that if the government R\&D subsidies are too small, the market failure of technological innovation activities would not be significantly improved, and then too much government R\&D subsidies would substitute firm's innovation expenditures. Guellec (2003) [11] found that firm’s R\&D investment increased with the increasing government R\&D subsidies, yet to

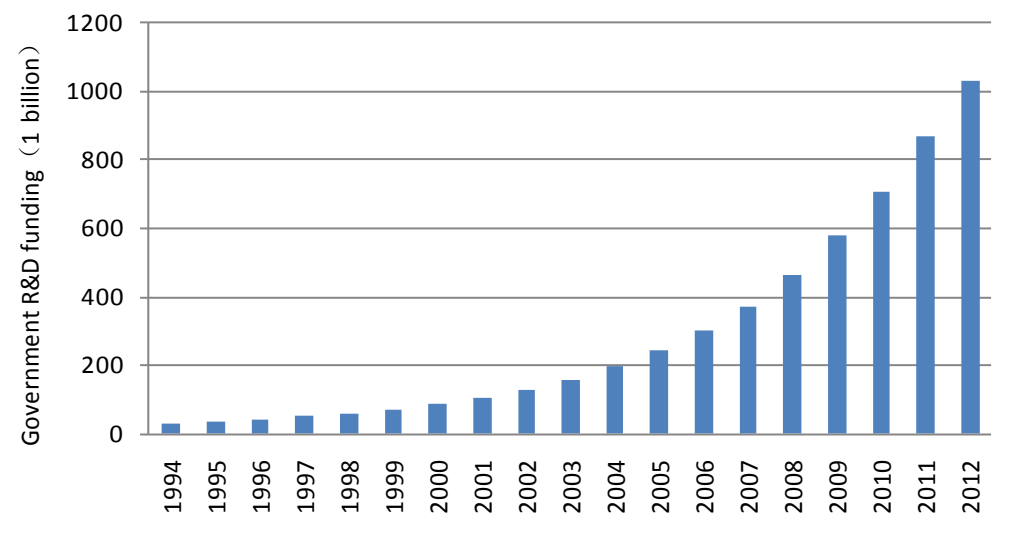

Figure 1. Government funding on science and technology in China. 
a point. Beyond this threshold, a greater share of government R\&D subsidies will reduce firms' innovative enthusiasm. Li and Wang (2010) [12] used Chinese 2001-2008 provincial panel data to conclude that government R\&D subsidies had a significant interval effect to firms' innovative performance. So Görg and Strobl (2007) [13] proposed that government R\&D subsidies should be maintained at an appropriate scale. Therefore:

Hypothesis 1. An inverted U-shaped relationship exists between the share of government R\&D subsidies and a firm's innovative performance.

Based on the above theoretical foundation, this paper adds firm's R\&D capacity factor to analysis the efficiency of government R\&D subsidies. First of all, from the point of view of Resource Based Theory [14], scientific knowledge is the cornerstone of innovation, also science and technology can enhance the product improvement and innovation efficiency, shorten the new product development time, and accelerate the pace of listing (Karlsson \& Ahlstrom, 1999) [15]. According to the dynamic capability view of resource based theory [16], technical ability is a process of continuous, dynamic learning and accumulation, some valuable knowledge and information are being identified, absorbed and digested, and then integrate them with firms' own resources, formed abilities to produce new goods and services. Lundvall and Nielsen (1999) [17] propose that R\&D capacity and high quality of human resource is the key to firms' successful innovation. High R\&D capacity can effectively acquire, absorb and apply external knowledge to develop and produce new products and processes to better compete and survive in the market. Through its R\&D activities, a firm can build up a stock of knowledge about specific fields of technology, which connects to its products. With the time goes, the firm becomes skilled in its processes and accesses to government R\&D subsidies for rational use (Cohen \& Levinthal, 1990) [18]. So governments tend to subsidy the firm which has a certain R\&D capacity (David \& Nestor) [19]. The famous Schumpeter's Hypotheses proposed that the size resource of a firm is the basic condition for innovation. Galbraith (1956) [20] has further emphasized the importance of firm's scale in innovation. They believe that big firm is the most effective inventor and creator for technical innovation. Cheng (2009) [21] also finds that the bigger firm, the better incentive effect on government R\&D subsidies by using Chinese data. This is due to the advantage in large firm, they have matching capital and talent to ensure the successful implementation of the project by obtaining the government R\&D subsidies. Therefore, the government also tends to subsidy the larger firms. Export is another firm characteristic, which can identify whether the firm engages in export activities. Firms engage in international market are more likely to devote their efforts to innovation activities to pursue stronger competition than those in domestic market (Basile, 2001) [22]. At the same time, industry and time characteristics are the factors that must be considered. High-tech industry has higher technical level and development potential, so it will have more innovative performance (Tsai \& Wang, 2004) [23]. With the time goes, social productivity is being increased and some R\&D policies are formulated, that are conductive to innovative performance. Based on the above analysis, this paper further examines the influence of these factors to the effect of government R\&D subsidies, which will provide some references to formulate R\&D subsidy policies.

Hypothesis 2a. The inverted U-shaped relationship between the share of government R\&D subsidies and innovative performance is moderated by $R \& D$ capacity in such a way that greater $R \& D$ capacity is associated with a higher point of maximum in the inverted U-shaped curve.

Hypothesis $2 b$. The inverted U-shaped relationship between the share of government R\&D subsidy and innovative performance is moderated by R\&D capacity in such a way that greater R\&D capacity is associated with a higher point of maximum efficiency in the inverted U-shaped curve for a smaller share of government R\&D subsidy.

\section{Research Design and Models}

\subsection{Data}

The data used for this study was based on panel data of 1997-2012 Chinese large and medium enterprises. Since promulgated "People's Republic of China S\&T Progress Law" in 1993, the most influential policy is the implementation of "People's Republic of China, Promoting the Transformation of Scientific and Technological achievement" in 1996. The law identifies the principles during the transformation of S\&T achievement, and it provides safeguards, technical right and ownership to promote the transformation of S\&T, so this year is a turning point. We choose year 1997 as the beginning point. Then, the advantage of panel data is that it can contain a large amount of information, which can reduce the influence of multicollinearity among variables, increase degrees of freedom and the effectiveness of estimation. Panel data facilitate the dynamic adjustment and control individual heterogeneity. Because private sector $\mathrm{R} \& \mathrm{D}$ strength is mainly concentrated in large and medium en- 
terprises, which are the main objects of government R\&D subsidies.

- Dependent variable. To measure a firm's innovative performance, the China Statistical Yearbook on Science and Technology reports the turnover of new or significantly improved products. Dependent variable is used as the logarithmic form of the innovative sales, which is often used in innovation studies (Cassiman and Veugelers, 2006; Tsai, 2009) [24] [25], because it can directly measure the success of new or significantly improved products in the market.

- Independent variable. The first independent variable is government R\&D subsidies, Gov R\&D for short, can capture the extent to which firms get government subsidy. It is expressed as the percentage in firm's R\&D expenditure. The value of Gov R\&D variable goes from zero to $100 \%$. The second independent variable, R\&D capacity, should capture the inherently cumulative process that the development of a firm's stock of knowledge entails. In the study R\&D capacity is calculated as the number of employees working in the firm (Cassiman and Veugelers, 2002; Veugelers, 1997) [26] [27].

- Control variable. Prior research suggests that there are specific factors that influence a firm's innovative performance, which need to be controlled. For example, the size is the well-known factors that affect a firm's innovative performance. Firm's size is included as the logarithmic form of the assets. Export identifies whether the firm engages in export activities. Firms engage in international market hungry for innovation because of stronger competition [28]. Finally, wave2006 and industry dummies are present in the sample.

\subsection{Models}

The classical method to measure the effect of government R\&D subsidies on a firm's innovative performance is based on the study of Luca Berchicci [29]. The Gov R\&D and R\&D capacity are as the control variables, then the innovative sales as the dependent variable. To test the above-mentioned hypotheses, two models are proposed. The first model investigates the effect of government R\&D subsidies on innovative performance for firm i that perform R\&D activities.

$$
\begin{aligned}
& \text { Innovative sales }_{i}=\beta_{0}+\beta_{1} \mathrm{R} \& \mathrm{D} \text { capacity }_{i}+\beta_{2} \mathrm{Gov}_{\mathrm{R}} \& \mathrm{D}_{i}+\beta_{3} \mathrm{Gov}_{\mathrm{R}} \& \mathrm{D}_{i}{ }^{2} \\
& +\beta_{4} \ln \left(\text { Size }_{i}\right)+\beta_{5} \text { Export }_{i}+\beta_{6} \text { wave } \text { Industry dummies }+\varepsilon_{i}
\end{aligned}
$$

The second model investigates how R\&D capacity moderates the relationship between the share of government R\&D subsidies and innovative performance. The equation adds a linear by linear interaction between R\&D capacity and government R\&D subsidies to Equation (1).

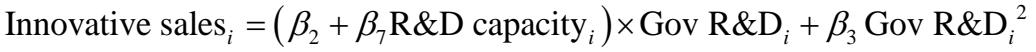

$$
\begin{aligned}
& +\left(\beta_{1} \text { R\&Dcapacity }_{i}+\beta_{4} \ln \left(\text { Size }_{i}\right)+\beta_{5} \text { Export }_{i}+\beta_{6} \text { wave } \text { Industry dummies }+\beta_{0}\right)+\varepsilon
\end{aligned}
$$

where in Equation (2) $\left(\beta_{2}+\beta_{7} \mathrm{R} \& \mathrm{D}\right.$ capacity $)$ indicates the overall linear trend of innovative sales on government $\mathrm{R} \& \mathrm{D}$ subsidies at one or more values of $\mathrm{R} \& \mathrm{D}$ capacity. If $\left(\beta_{2}+\beta_{7} \mathrm{R} \& \mathrm{D}\right.$ capacity $\left.\mathrm{i}_{\mathrm{i}}\right)$ is positive, there has an overall upward linear trend, otherwise it has an overall downward linear trend.

\section{Empirical Results}

Table 1 presents the descriptive statistics and correlation coefficient between variables. In this table we can see all the correlation coefficient is less than 0.68 , that is to say there is no collinearity between variables. Then Table 1 shows a negative and weak correlation between R\&D capacity and government R\&D subsidies $(-0.08)$. It suggests that as the firm is enthusiasm to engage in R\&D activities, it will have high R\&D investment and low proportion of government R\&D subsidy. The correlation between R\&D capacity and innovative sales is positive (0.18), then firm's size, export, wave2006 and industry dummies all have positive correlation with the dependent variable.

According to the characteristics of panel data model, this paper can't use fixed effects model to analyze because the existence of dummy variables, so we take random model. First of all, the heteroscedasticity and autocorrelation test is needed. Table 2 shows that heteroscedasticity and autocorrelation existed in the model, so we need to modify the random effects results. 
Table 1. Descriptive statistics.

\begin{tabular}{|c|c|c|c|c|c|c|c|c|c|}
\hline & Variables & Mean & S.D. & 1 & 2 & 3 & 4 & 5 & 6 \\
\hline 1 & Innovative sales & 6.2294 & 1.142 & 1 & & & & & \\
\hline 2 & R\&D capacity & 0.0360 & 0.024 & 0.18 & 1 & & & & \\
\hline 3 & Gov R\&D & 0.044 & 0.053 & 0.21 & -0.08 & 1 & & & \\
\hline 4 & Size & 4.712 & 0.570 & 0.13 & 0.31 & 0.05 & 1 & & \\
\hline 5 & Export & 3.332 & 2.132 & 0.12 & 0.03 & 0.15 & 0.4 & & \\
\hline 6 & Wave2006 & 0.430 & 0.252 & 0.25 & -0.13 & -0.14 & -0.34 & 1 & \\
\hline 7 & Industry dummies & 0.219 & 0.143 & 0.27 & 0.68 & 0.08 & 0.58 & -0.4 & 1 \\
\hline
\end{tabular}

Table 2. Heteroscedasticity and autocorrelation test.

\begin{tabular}{ccccc}
\hline Indicator & Model 1 & Model 2 & Model 3 & Model 4 \\
\hline chi2 & 4332.85 & 2250.72 & 2414.52 & 2556.89 \\
Prob > chi2 & 0.0000 & 0.0000 & 0.0000 & 0.0000 \\
F & 17.772 & 17.835 & 17.849 & 17.268 \\
Prob > F & 0.0000 & 0.0000 & 0.0001 & 0.0000 \\
\hline
\end{tabular}

Table 3 presents the modified regression results. Model 1 shows the relationship between the control variables and innovative performance. Firm's size and export positively affect innovative performance, while the industry dummies variable is not significant. Then is R\&D capacity, its coefficient is positive and significant. This finding suggests that building a stock of knowledge strongly influences a firm's innovative performance.

Model 2 adds the Gov R\&D variable, which shows a negative yet not significant effect on innovative performance. Model 3 investigates whether the relationship between Gov R\&D and innovative performance has a non-linear effect. The Gov R\&D squared variable is included. The Gov R\&D variable has a positive and significant coefficient while Gov R\&D squared coefficient is negative and significant. Model 3 also shows a larger chi-square value than Model 2. This reveals that the addition of the main effect of Gov R\&D and its squared term increases the explanatory power of the model. Taken together, these two effects reveal that Gov R\&D has a curvilinear effect on innovative performance. To ease the interpretation, these effects are shown graphically. Figure 2 illustrates an inverted U-shaped line that captures the relationship between Gov R\&D and innovative sales. It implies that firms that received government R\&D subsidies have greater benefits in term of innovative performance yet up to a point of $13.2 \%$. Beyond this threshold, greater government R\&D subsidies reduce a firm's innovative performance.

Turning to Hypotheses 2a and 2b, Model 4 indicates the conditional effect of R\&D capacity on the relationship between Gov R\&D and innovative performance by applying Equation (2). The interaction variable (R\&D capacity $\times$ Gov R\&D) is positive and significant. This result shows that R\&D capacity not only influences a firm's innovation performance directly but also the relationship between government R\&D subsidies and firms' innovative performance. However, it is not immediately apparent from the model 4 how its conditional effect works on the given relationship. Aiken (1991) [30] suggested that one approach is to graph the main effects given the conditional effect under study.

Based on Equation (2), Figure 3 shows three linear trends of innovative performance on government R\&D subsidies at three values of R\&D capacity variable. “Average R\&D capacity” captures the R\&D capacity variable at its mean value (line with a dot mark), "low R\&D capacity" at half standard deviation below its mean (cruciform line) and "high R\&D capacity" at half standard deviation above the mean (fork mark). When the R\&D capacity is at its mean value, the curve in Figure 2 and Figure 3 show a similar trend. Relevant findings are found when R\&D capacity moves away from the mean. As shown in Figure 3, higher R\&D capacity is associated with greater innovative performance at a lower level of Gov R \& D. For the firms with high R\&D capacity, the maximum efficiency-the optimal value of Gov R\&D where the maximum performance value is 
Table 3. Gov R\&D and innovative performance and the moderating effect of R\&D capacity.

\begin{tabular}{|c|c|c|c|c|}
\hline \multirow{2}{*}{ Independent variables } & \multicolumn{4}{|c|}{ Innovative sales as dependent variable } \\
\hline & Model 1 & Model 2 & Model 3 & Model 4 \\
\hline \multirow{2}{*}{ R\&D capacity } & $19.53^{* * *}$ & $19.85^{* * *}$ & $19.76^{* * *}$ & $12.26 * * *$ \\
\hline & 14.41 & 14.03 & 14.04 & 7.08 \\
\hline \multirow{2}{*}{ Size } & $0.317 * * *$ & $0.324 * * *$ & $0.334 * * *$ & $0.326^{* * *}$ \\
\hline & 6.05 & 5.94 & 6.06 & 6.21 \\
\hline \multirow{2}{*}{ Export } & $1.608 * * *$ & $1.607 * * *$ & $1.608 * * *$ & $1.622^{* * *}$ \\
\hline & 11.27 & 11.23 & 11.19 & 11.34 \\
\hline \multirow{2}{*}{ Wave2006 } & $0.0861 * * *$ & $0.0837 * * *$ & $0.0834 * * *$ & $0.0835^{* * *}$ \\
\hline & 14.62 & 14.3 & 14.36 & 14.74 \\
\hline \multirow{2}{*}{ Industry dummies } & -0.166 & -0.203 & -0.248 & -0.198 \\
\hline & $(-0.56)$ & $(-0.67)$ & $(-0.82)$ & $(-0.71)$ \\
\hline \multirow{2}{*}{ Gov R\&D } & & 2.571 & $1.078^{*}$ & $-5.117 * *$ \\
\hline & & $(0.77)$ & -2.17 & $(-3.25)$ \\
\hline \multirow{2}{*}{ Gov R\&D squared } & & & $-4.083 * * *$ & -8.589 \\
\hline & & & $(-3.35)$ & $(-1.69)$ \\
\hline \multirow{2}{*}{ R\&D capacity $\times$ Gov R\&D } & & & & $146.4^{* * *}$ \\
\hline & & & & 5.7 \\
\hline \multirow{2}{*}{ constant } & $3.487 * * *$ & $3.488 * * *$ & $3.426 * * *$ & $3.552^{* * *}$ \\
\hline & 14.41 & 14.23 & 13.64 & 15.02 \\
\hline obs & 593 & 593 & 593 & 593 \\
\hline Log likelihood & -539.2825 & -779.6141 & -779.2744 & -763.2764 \\
\hline Wald chi2 & 616.82 & 600.13 & 606.42 & 718.15 \\
\hline Prob $>$ chi2 & 0.0000 & 0.0000 & 0.0000 & 0.0000 \\
\hline
\end{tabular}

${ }^{*} \mathrm{p}<0.1,{ }^{* *} \mathrm{p}<0.05,{ }^{* * *} \mathrm{p}<0.01$.

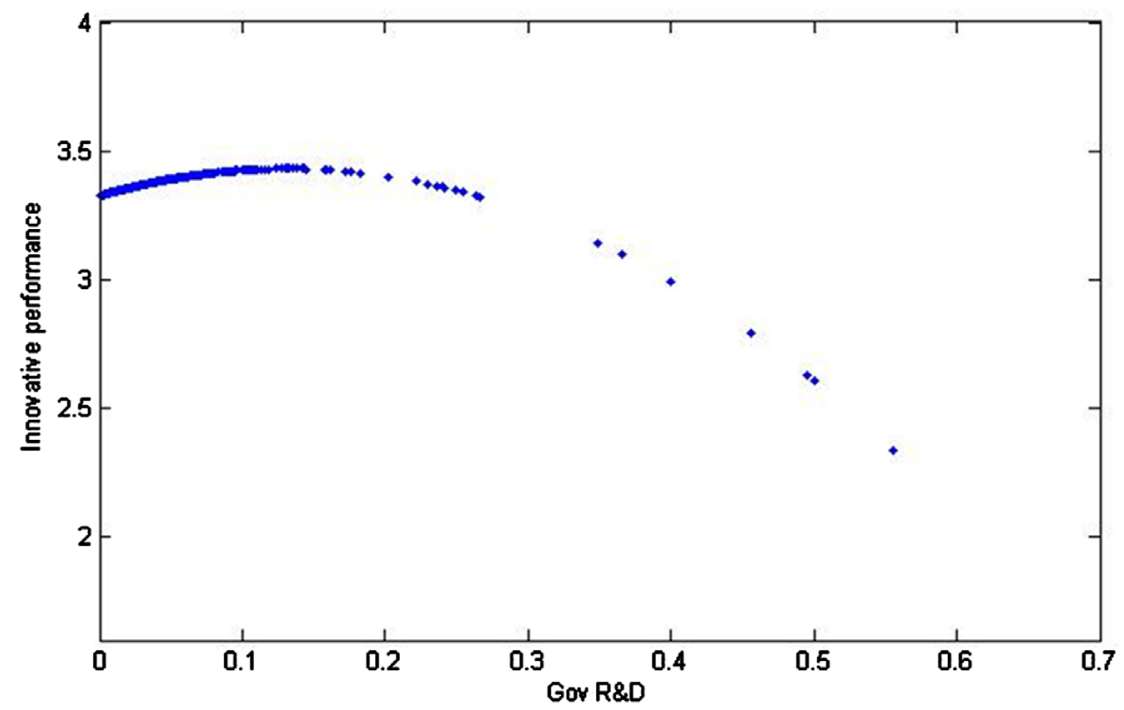

Figure 2. The relationship between Gov R\&D and innovative performance. 


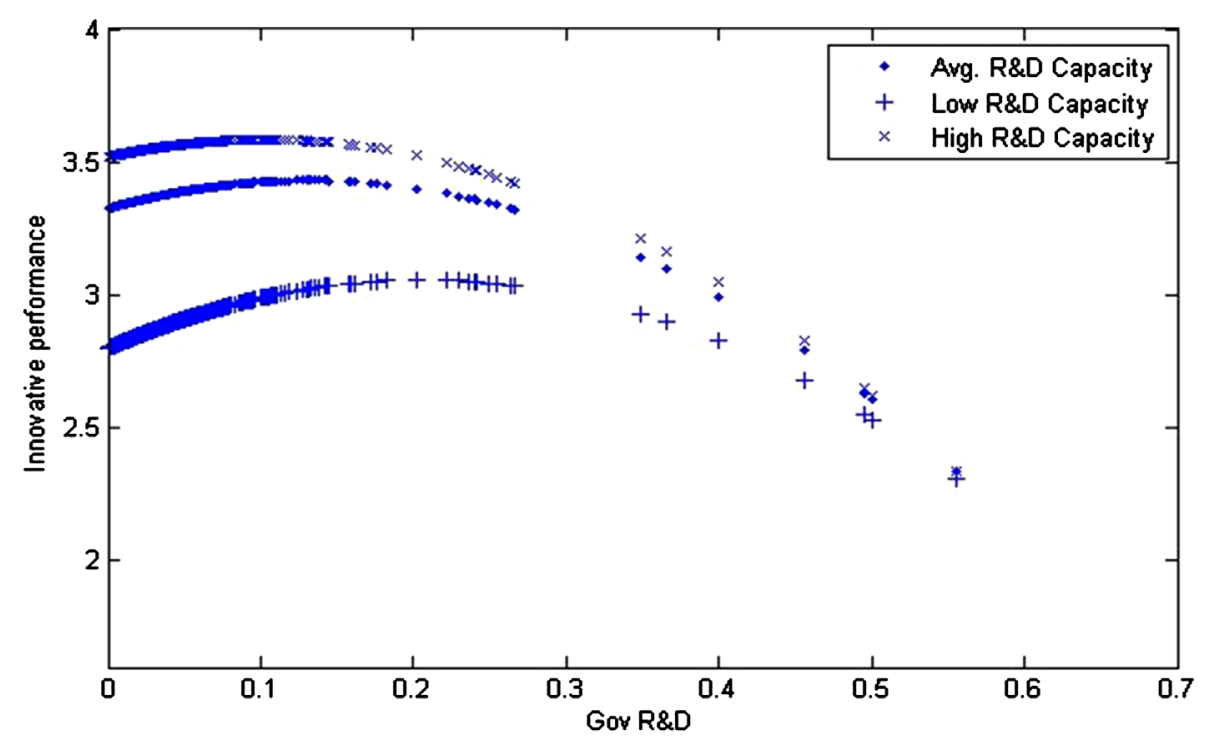

Figure 3. The moderating effect of R\&D capacity on the relationship between Gov R\&D and innovative performance.

achieved is at $10.96 \%$ of Gov R\&D, while for firms with low R\&D capacity the equilibrium point is at $24.3 \%$ of Gov R\&D. These findings imply that firms with greater R\&D capacity will use government subsidies efficiently. These firms enthusiasm to innovation and consciously increase their R\&D investment, so the proportion of government subsidies relatively less. As the Gov R\&D variable increases, the three curves tend to converge. This confluence may reconfirm that greater government R\&D subsidies is detrimental for innovative performance regardless of the R\&D capacity of firms. Taken together, these findings indicate that both Hypotheses 2a and 2b are supposed. So our government R\&D policy should pay more attention to the optimal allocation of resources and consider whether the target firm has the ability to reach certain level of innovation. So government should identify a "degree" according to different firms.

In china, statistical patent is one of important means to analysis the technological progress because of its easily available and innovated related. It can become stable and objective evaluation criteria. Since not all patent applications will be authorized, the authorized indicator may reduce the true level of innovation [31]. So the number of patent application can more objectively reflect the current innovation output. So the patent applications will be used as dependent variable to verify the above hypothesis. Table 4 replicates the estimations in Table 3. Model 3 confirms that the curvilinear relationship between the government R\&D subsidies and innovative performance, and Model 4 corroborates the conditional effect of R\&D capacity on the relationship between government $\mathrm{R} \& \mathrm{D}$ subsidies and innovative performance. These results confirm and strengthen the explanatory power of the model.

The above-mentioned empirical tests assume that the main variables are exogenous - they are not correlated with the error term. However, this may not be the case since the Gov R\&D variable and the interaction term may not be strictly exogenous. Thus, this final test assumes that our main independent variables are endogenous and thus requires an estimation method that includes instrumental variables. We must find some valid instruments that are uncorrelated with the errors, but correlated with the endogenous variables and dependent variables. With weak instrument variables the results are likely to be biased in the same way of OLS estimation. To cope with this problem, we use Arellano-Bond difference GMM estimator [32]. The AB estimator combines instrument variables (the dependent variable lagged on period) and it is suitable for panel data with few time periods and a great number of observations of individuals (Roodman, 2006) [33]. Table 5 shows the AB estimations. Overall, the results confirm the suggested hypotheses.

\section{Discussion}

This paper comes to the conclusions and discussions that government R\&D subsidies have a vital significance for promoting firm's innovative performance. How to formulate R\&D policy effectively and how to improve 
Table 4. Gov R\&D and innovative performance.

\begin{tabular}{|c|c|c|c|c|}
\hline \multirow{2}{*}{ Independent variables } & \multicolumn{4}{|c|}{ Number of patent application as dependent variable } \\
\hline & Model 1 & Model 2 & Model 3 & Model 4 \\
\hline \multirow{3}{*}{ R\&D capacity } & $15.03 * * *$ & $14.89 * * *$ & $14.74 * * *$ & $12.42 * * *$ \\
\hline & & & & \\
\hline & -17.08 & 15.54 & 15.27 & 9.88 \\
\hline \multirow[b]{2}{*}{ Size } & $-0.137 * * *$ & $-0.124 * * *$ & $-0.116^{* *}$ & $-0.126 * * *$ \\
\hline & $(-3.96)$ & $(-3.36)$ & $(-3.11)$ & $(-3.49)$ \\
\hline \multirow{3}{*}{ Export } & $0.001^{* * *}$ & $0.001 * * *$ & $0.001 * * *$ & $0.001 * * *$ \\
\hline & & & & \\
\hline & 14.13 & 14.08 & 14.04 & 13.95 \\
\hline \multirow{2}{*}{ Wave2006 } & $0.146 * * *$ & $0.146^{* * *}$ & $0.146 * * *$ & $0.146^{* * *}$ \\
\hline & 35.62 & 34.06 & 34.1 & 34.96 \\
\hline \multirow{3}{*}{ Industry dummies } & $0.671^{* * *}$ & $0.638^{* *}$ & $0.599 * *$ & $0.648^{* *}$ \\
\hline & & & & \\
\hline & 3.51 & 3.14 & 2.92 & 3.27 \\
\hline \multirow{3}{*}{ Gov R\&D } & & 0.0382 & $1.462 *$ & -0.78 \\
\hline & & & & \\
\hline & & $(0.09)$ & $(2.15)$ & $(-0.66)$ \\
\hline \multirow{2}{*}{ Gov R\&D squared } & & & $-5.048 * *$ & -3.13 \\
\hline & & & $(-3.95)$ & $(-1.12)$ \\
\hline \multirow[b]{2}{*}{ R\&D capacity $\times$ Gov $R \& D$} & & & & $42.28 *$ \\
\hline & & & & 2.39 \\
\hline \multirow{3}{*}{ constant } & $3.373 * * *$ & $3.342 * * *$ & $3.290 * * *$ & $3.406 * * *$ \\
\hline & & & & \\
\hline & 8.42 & 7.69 & 7.21 & 8.1 \\
\hline obs & 590 & 590 & 590 & 590 \\
\hline Log likelihood & -510.7471 & -525.2515 & -512.2151 & -505.3267 \\
\hline Wald chi2 & 1749.03 & 1753.96 & 18215.12 & 1824.61 \\
\hline Prob $>$ chi2 & 0.000 & 0.000 & 0.000 & 0.000 \\
\hline
\end{tabular}

${ }^{*} \mathrm{p}<0.1,{ }^{* *} \mathrm{p}<0.05, * * * \mathrm{p}<0.01$

the R\&D subsidy efficiency is important for the sustainable development of China's economy. First, Chinese government needs to improve the R\&D subsidies. From Figure 2 and Figure 3 we know that the share of government $R \& D$ subsidies mostly concentrate in the range of $0-0.1$, which is far smaller than that of the developed countries. Second, this study reaffirms the central role of firm's internal R\&D capacity in moderating the relationship between government $\mathrm{R} \& \mathrm{D}$ subsidies and innovative performance. The results demonstrate that a firm's own stock of knowledge can greatly contribute to a greater innovative performance. Firms with greater R\&D capacity perform systematically better than those with a lower level of R\&D capacity, and they reach the optimum of innovative performance with less government R\&D subsidies, as Figure 3 illustrates. Thus, how a firm manages its R\&D capacity influences its innovative performance. 
Table 5. Arellano-Bond GMM estimator.

\begin{tabular}{|c|c|c|c|c|}
\hline \multirow{2}{*}{ Independent variables } & \multicolumn{4}{|c|}{ Dependent variable lagged on period as instrumental variable } \\
\hline & Model 1 & Model 2 & Model 3 & Model 4 \\
\hline \multirow[b]{2}{*}{ Innov $_{t-1}$} & $0.441 * * *$ & $0.451 * * *$ & $0.450 * * *$ & $0.480 * * *$ \\
\hline & 9.69 & 9.89 & 9.92 & 9.87 \\
\hline \multirow{2}{*}{ R\&D capacity } & $4.502 * * *$ & $4.909 * * *$ & $5.123 * * *$ & $6.498 * * *$ \\
\hline & 3.63 & 3.96 & 4.13 & 4.63 \\
\hline \multirow{2}{*}{ Size } & $0.0727 *$ & $0.0634 *$ & $0.0655^{*}$ & $0.0679 *$ \\
\hline & 2.34 & 2.05 & 2.12 & 2.17 \\
\hline \multirow{2}{*}{ Export } & $1.213^{* * *}$ & $1.436 * * *$ & $1.165^{* * *}$ & $1.209 * * *$ \\
\hline & 8.61 & 8.65 & 9.01 & 8.57 \\
\hline \multirow{2}{*}{ Wave2006 } & $0.0759^{* * *}$ & $0.0763^{* * *}$ & $0.0767 * * *$ & $0.0725^{* * *}$ \\
\hline & 10.34 & 10.46 & 10.59 & 9.43 \\
\hline \multirow[b]{2}{*}{ Industry dummies } & -0.358 & -0.357 & -0.367 & -0.367 \\
\hline & $(-1.67)$ & $(-1.67)$ & $(-1.73)$ & $(-1.70)$ \\
\hline \multirow[b]{2}{*}{ Gov R\&D } & & $0.752^{*}$ & $2.198 * *$ & $3.238 * * *$ \\
\hline & & 2.53 & 2.72 & 3.33 \\
\hline \multirow[b]{2}{*}{ Gov R\&D squared } & & & -4.785 & -4.733 \\
\hline & & & $(-1.95)$ & $(-1.90)$ \\
\hline \multirow[b]{2}{*}{ R\&D capacity $\times$ Gov $R \& D$} & & & & $-36.38 *$ \\
\hline & & & & $(-2.11)$ \\
\hline \multirow{2}{*}{ constant } & $3.401^{* *}$ & $3.401 * *$ & $3.344^{*}$ & 3.26 \\
\hline & 2.76 & 2.76 & 2.31 & 1.66 \\
\hline $\mathrm{N}$ & 543 & 543 & 543 & 543 \\
\hline Wald chi2 & 3487.27 & 3545.59 & 3580.36 & 3492.20 \\
\hline Prob > chi2 & 0.000 & 0.000 & 0.000 & 0.000 \\
\hline
\end{tabular}

${ }^{*} \mathrm{p}<0.1,{ }^{* *} \mathrm{p}<0.05,{ }^{* * *} \mathrm{p}<0.01$

In summary, this paper contributes to our understanding of the effect of government R\&D subsidies on firm's innovative performance. Firms with high level of R\&D capacity can absorb the government R\&D subsidies effectively and the finding provides some managerial implication as well. The managers of firms need to take into account their own technological knowledge base and R\&D capabilities. This study thoroughly examines the role of government R\&D subsidies and R\&D capacity on a firm's innovative performance, yet it is faced with some important limitations. There still exist restrictions on the choice of indicators to measure variables. Then larger longitudinal set firms can have a greater exploratory power. Future research could focus on the factors affecting the innovative performance and provide an even more thorough examination of the role of R\&D capacity on a firm's performance. 


\section{Acknowledgements}

This paper is supported by National Natural Science Foundation of China (No. 71371113), Shanxi Province Office of Education Research (No. 2012205), Ministry of Education in China (MOE) Project of Humanities and Social Sciences (No. 13YJA790154). The authors thank the anonymous reviewers, whose suggestions are useful in putting the paper in its present form. The special gratitude goes to the authors' English-teaching friend. However, the authors are responsible for any errors that remain in the paper.

\section{References}

[1] Schumpete, J.A. (1912) The Theory of Economic Development. Harvard University Press, Cambridge, MA.

[2] Arrow, K. (1962) Economic Welfare and the Allocation of Resources for Invention. The Rate and Direction of Inventive Activity: Economic and Social Factors, 2, 609-626. http://www.nber.org/chapters/c2144.pdf

[3] Aghion, P., Howitt, P. and García, P.C. (1998) Endogenous Growth Theory. MIT Press, Cambridge, MA. http://scholar.harvard.edu/aghion/publications/endogenous-growth-theory

[4] Romer, P.M. (1990) Endogenous Technological Change. The Journal of Political Economy, 98, S71-S102. http://www.jstor.org/discover/10.2307/2937632?uid=3737800 \& uid=2 \& uid=4 \& sid=21104369141647

[5] Grossman, G.M. and Helpman, E. (1991) Innovation and Growth in the Global Economy. MIT Press, Cambridge, MA.

[6] Spence, M. (1984) Cost Reduction, Competition, and Industry Performance. Econometrica: Journal of the Econometric Society, 52, 101-121. http://dx.doi.org/10.2307/1911463 http://www.jstor.org/discover/10.2307/1911463?uid=3737800 \& uid=2 \& uid=4 \& sid=21104369141647

[7] Benat, B.O. and Andres, R.P. (2004) From R\&D to Innovation and Economic Growth in the EU. Growth and Change, 35, 434-455. http://dx.doi.org/10.1111/j.1468-2257.2004.00256.x http://onlinelibrary.wiley.com/doi/10.1111/j.1468-2257.2004.00256.x/abstract

[8] Ministry of Science and Technology of the People’s Republic of China (2009) Report of the International Science and Technology Development. Science Press, Beijing. http://www.most.gov.cn/

[9] Chinese Scientific Development Strategy Research Group (2009) Annual Report of Science and Technology Development of China. Science Press, Beijing.

[10] Zhu, P.F. and Xu, W.M. (2003) On the Impact of Government S\&T Incentive Policy on the R\&D Input and Its Patent Output of Large and Medium-Sized Industry Enterprises in Shanghai. Economic Research Journal, 38, 45-53.

[11] Guellec, D. and Potterie, B. (2003) The Impact of Public R\&D Expenditure on the Business R\&D. Economic Innovation New Technology, 12, 225-243. http://www.tandfonline.com/doi/abs/10.1080/10438590290004555

[12] Li, P. and Wang, C.H. (2010) The Nonlinear Study of Public S\&T Subsidies to Business Innovation: A Threshold Regression Analysis Based on Panel Data in 2001-2008. China Soft Science Magazine, 8, 138-147.

[13] Görg, H. and Strobl, E. (2007) The Effect of R\&D Subsidies on Private R\&D. Economica, 74, 215-234. http://onlinelibrary.wiley.com/doi/10.1111/j.1468-0335.2006.00547.x/full http://dx.doi.org/10.1111/j.1468-0335.2006.00547.x

[14] Barney, J.B. and Clark, D.N. (2007) Resource-Based Theory: Creating and Sustaining Competitive Advantage. Oxford University Press, Oxford. http://library.wur.nl/WebQuery/clc/1882076

[15] Karlsson, C. and Ahlstrom, P. (1999) Technological Level and Product Development Cycle Time. Journal of Product Innovation Management, 16, 352-362. http://onlinelibrary.wiley.com/doi/10.1111/1540-5885.1640352/abstract

[16] Kim, L. (2000) The Dynamics of Technological Learning in Industrialization. International Social Science Journal, 53, 297-308.

http://onlinelibrary.wiley.com/doi/10.1111/1468-2451.00316/abstract?deniedAccessCustomisedMessage=\&userIsAuth enticated=false

[17] Lundvall, B.A. and Nielsen, P. (1999) Competition and Transformation in the Learning Economy-Illustrated by the Danish Case. Revue d'Économie Industrielle, 88, 67-89. http://dx.doi.org/10.3406/rei.1999.1745 http://www.persee.fr/web/revues/home/prescript/article/rei_0154-3229_1999_num_88_1_1745

[18] Cohen, W.M. and Levinthal, D.A. (1990) Absorptive-Capacity: A New Perspective on Learning and Innovation. Administrative Science Quarterly, 35, 128-152. http://www.jstor.org/discover/10.2307/2393553?uid=3737800 \& uid=2 \& uid=4 \& sid=21104369141647

[19] David, M.L. and Nestor, E.T. (1983) Effects of Government R\&D on Private R\&D Investment and Productivity: A Macroeconomic Analysis. The Bell Journal of Economics, 14, 551-561. http://www.jstor.org/discover/10.2307/3003656?uid=3737800 \& uid=2 \& uid=4 \& sid=21104369141647 
[20] Galbraith, J.K. (1956) American Capitalism. Houghton Mifflin, Boston.

[21] Cheng, H. and Zhao, X. (2009) Spillovers from Publicly Financed Business R\&D: Empirical Evidence from Large and Medium-Sized Industry Enterprise of China. Studies in Science of Science, 27, 862-868. http://www.doc88.com/p-90394270771.html

[22] Basile, R. (2001) Export Behavior of Italian Manufacturing Firms over the Nineties: The Role of Innovation. Research Policy, 30, 1185-1201. http://www.sciencedirect.com/science/article/pii/S0048733300001414 http://dx.doi.org/10.1016/S0048-7333(00)00141-4

[23] Tsai, K. and Wang, J. (2004) R\&D Productivity and the Spillover Effects of High-Tech Industry on the Traditional Manufacturing Sector: The Case of Taiwan. The World Economy, 27, 1555-1570. http://onlinelibrary.wiley.com/doi/10.1111/j.1467-9701.2004.00666.x/abstract http://dx.doi.org/10.1111/j.1467-9701.2004.00666.x

[24] Cassiman, B. and Veugelers, R. (2006) In Search of Complementarity in Innovation Strategy: Internal R\&D and External Knowledge Acquisition. Management Science, 52, 68-82. http://dx.doi.org/10.1287/mnsc.1050.0470 http://pubsonline.informs.org/doi/abs/10.1287/mnsc.1050.0470

[25] Tsai, K.H. (2009) Collaborative Networks and Product Innovation Performance: Toward a Contingency Perspective. Research Policy, 38, 765-778. http://dx.doi.org/10.1016/j.respol.2008.12.012 http://www.sciencedirect.com/science/article/pii/S004873330900002X

[26] Cassman, B. and Veugelers, R. (2002) R\&D Cooperation and Spillovers: Some Empirical Evidence from Belgium. American Economic Review, 92, 1169-1184. http://www.jstor.org/discover/10.2307/3083305?uid=3737800 \& uid=2 \& uid=4 \& sid=21104369141647

[27] Veugelers, R. (1997) Internal R\&D Expenditures and External Technology Sourcing. Research Policy, 26, 303-315. http://www.sciencedirect.com/science/article/pii/S004873339700019X http://dx.doi.org/10.1016/S0048-7333(97)00019-X

[28] Wakelin, K. (1998) Innovation and Export Behavior at the Firm Level. Research Policy, 26, 829-841. http://www.sciencedirect.com/science/article/pii/S0048733397000516 http://dx.doi.org/10.1016/S0048-7333(97)00051-6

[29] Berchicci, L. (2013) Towards an Open R\&D System: Internal R\&D Investment, External Knowledge Acquisition and Innovative Performance. Research Policy, 42, 117-127. http://dx.doi.org/10.1016/j.respol.2012.04.017 http://www.sciencedirect.com/science/article/pii/S0048733312001266

[30] Aiken, L.S., West, S.G. and Reno, R.R. (1991) Multiple Regression: Testing and Interpreting Interactions. Sage Publications, Newbury Park.

[31] Lu, H.L., Zhou, Y. and Jiang, J. (2014) Research on Relationship between R\&D Investment, Patent Output and Technical Market Development of Chongqing. Science and Technology Management Research, 4, 90-96.

[32] Arellano, M. and Bond, S. (1991) Some Tests of Specification for Panel Data-Monte-Carlo Evidence and an Application to Employment Equations. Review of Economic Studies, 58, 277-297. http://dx.doi.org/10.2307/2297968 http://restud.oxfordjournals.org/content/58/2/277.short

[33] Roodman, D. (2006) How to do Xtabond2: An Introduction to "Difference” and "System" GMM in Stata. Center for Global Development Working Paper No. 103. http://www.nuffield.ox.ac.uk/users/bond/file_HowtoDoxtabond8_with_foreword.pdf 
Scientific Research Publishing (SCIRP) is one of the largest Open Access journal publishers. It is currently publishing more than 200 open access, online, peer-reviewed journals covering a wide range of academic disciplines. SCIRP serves the worldwide academic communities and contributes to the progress and application of science with its publication.

Other selected journals from SCIRP are listed as below. Submit your manuscript to us via either submit@scirp.org or Online Submission Portal.
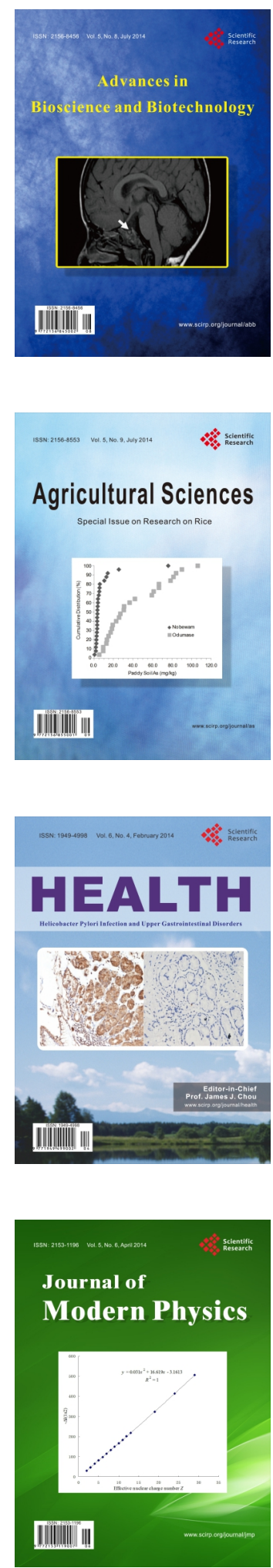
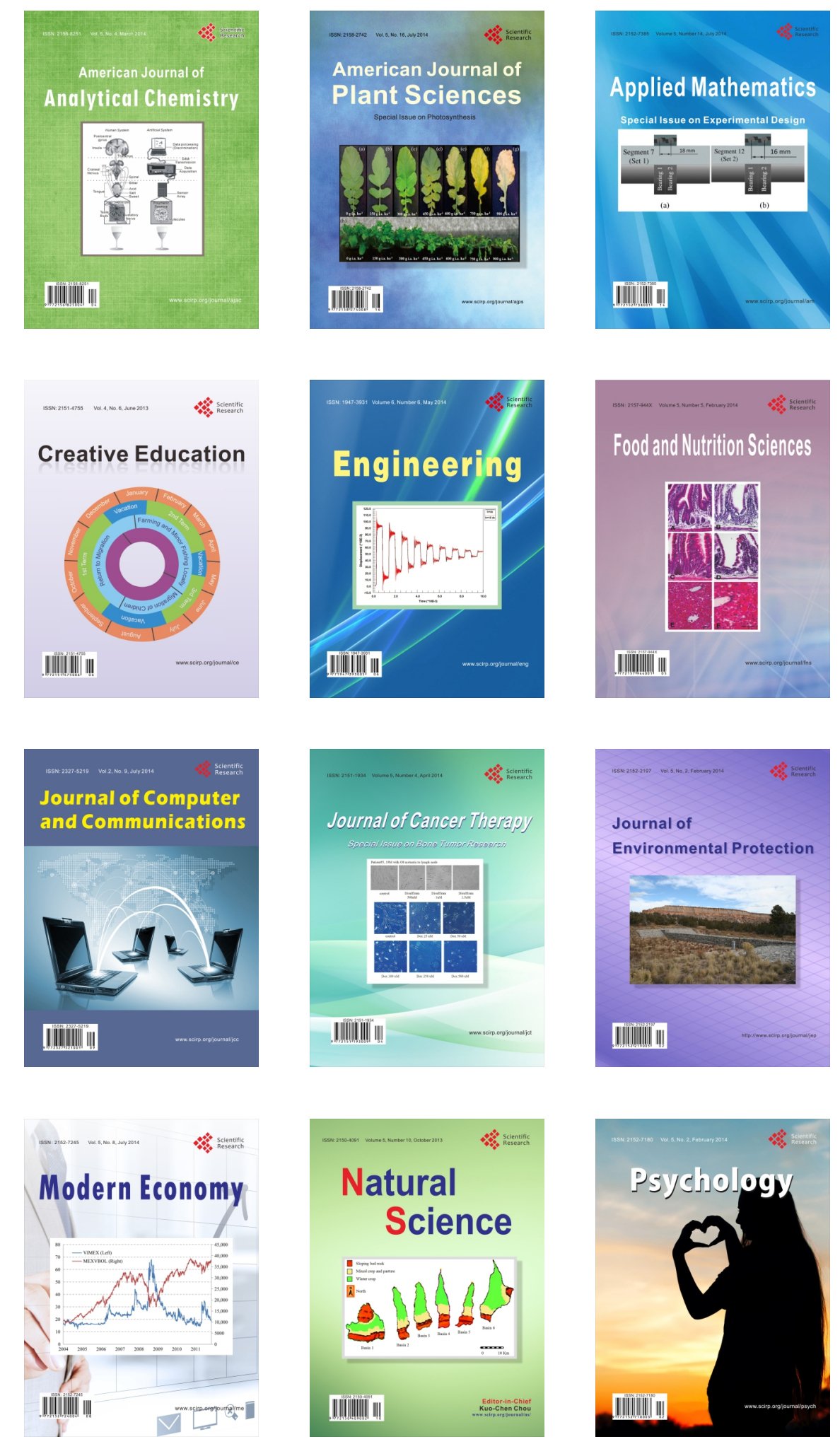